\title{
Efeito da modificação da composição química na sinterização e microestrutura de porcelanas de ossos bovinos
}

\section{(Effect of chemical composition modification on sinterability and microstructure of bone china)}

\author{
D. Gouvêa ${ }^{1}$, S. Hirakata ${ }^{1}$ H. Kahn ${ }^{2}$ \\ Laboratório de Processos Cerâmicos, Departamento de Engenharia Metalúrgica e de Materiais, Escola \\ Politécnica da Universidade de S. Paulo, Av. Prof. Mello Moraes 2463, S. Paulo, SP 05508-030 \\ Laboratório de Caracterização Tecnológica, Departamento de Engenharia Minas e de Petróleo, Escola \\ Politécnica da Universidade de S. Paulo - EPUSP, Av. Prof. Mello Moraes 2373, Cidade Universitária, S. Paulo, \\ SP 05508-030 \\ dgouvea@usp.br
}

\begin{abstract}
Resumo
Bone china é um tipo especial de porcelana que foi primeiramente desenvolvida no Reino Unido e é caracterizada pela alta resistência mecânica, grande alvura e translucidez. É fabricada com uma mistura de matérias-primas composta por aproximadamente $50 \%$ de cinza de ossos bovinos calcinados (OBC) e $25 \%$ de fundentes, $25 \%$ de caulim ou argilas plásticas. A modificação das proporções e tipos das matérias-primas originais, ou seja, a substituição de Cornish stone por feldspato para a fabricação de bone china acarreta numa alteração das proporções óxidos fundentes $/ \mathrm{SiO}_{2}$. Quando fabricada com Cornish stone, a composição é de 50:25:25 (OBC:caulim:Cornish stone). A fabricação de bone china nesta proporção com OBC:caulim:feldspato já apresenta uma maior fundência e uma temperatura de sinterização inferior, mas muito próxima, da composição original inglesa. A modificação para a composição 60:20:20 faz com que ocorra um aumento da relação fundentes/SiO, que leva a uma facilitação da sinterização devido à redução da viscosidade do vidro formado durante o processo. Nesta composição o material sinteriza a $1200{ }^{\circ} \mathrm{C}$, que é cerca de 80 ${ }^{\circ} \mathrm{C}$ abaixo da temperatura de queima da composição inglesa original, e apresenta uma microestrutura final muito homogênea e de baixa porosidade.

Palavras-chave: porcelana, bone china, sinterização.
\end{abstract}

\begin{abstract}
Bone china is a type of high quality porcelain body first developed in Britain in which calcined cattle bone (bone ash) is a major component (50\%), but with also Cornish stone (25\%) and kaolin (25\%). Whiteness, strength and high translucency are the characteristic features of this ware. Cornish stone acts as a flux in the bone china, melting first and acting as a solvent for the other constituents. In this work Cornish stone was substituted by feldspar as a flux and the mixtures 50:25:25, 50:30:20 and 60:20:20 (Bone Ash:feldspar:kaolin) were sintered from 1000 to $1300^{\circ} \mathrm{C}\left(50^{\circ} \mathrm{C}\right.$ steps). The samples were characterized by X-ray diffraction, mercury porosimetry, scanning electron microscopy, $X$-ray fluorescence and dilatometry. All samples sintered at temperatures lower than that of original bone china and the 60:20:20 composition presented complete densification at $1200{ }^{\circ} \mathrm{C}, 80{ }^{\circ} \mathrm{C}$ lower than the British pottery, and show a homogeneous microstructure.
\end{abstract}

Keywords: bone china, feldspar, sintering.

\section{INTRODUÇÃO}

Dentre os diferentes tipos de porcelanas, a que é fabricada com cinza de ossos bovinos (em inglês, bone china) é um tipo especial e que apresenta como principais características: alta resistência mecânica, grande alvura e translucidez [1-3]. É fabricada com uma mistura de matérias-primas, composta por aproximadamente $50 \%$ de cinza de ossos bovinos calcinados (OBC), $25 \%$ de fundentes e $25 \%$ de caulim ou outras argilas. Na Inglaterra esse tipo de produto foi originalmente fabricado utilizando como fundente o Cornish stone. Originária do sudoeste do Reino Unido da região de Cornwal, esta matéria-prima é composta principalmente por minerais do grupo dos feldspatos, mas contem também pequenos teores de quartzo sendo originado do intemperismo da decomposição de granitos de baixo teor de óxido de ferro [2].

Bone china é fabricada em processos de bi-queima onde, diferentemente das porcelanas de caulim, as cerâmicas são queimadas a $1280{ }^{\circ} \mathrm{C}$ para formar um corpo denso e translúcido, para só então serem esmaltadas em temperaturas menores $\left(1080{ }^{\circ} \mathrm{C}\right)$ [2]. Um dos grandes problemas da esmaltação desta porcelana é o seu elevado coeficiente de 
expansão térmica [4-6], que leva a uma séria dificuldade de acordo massa/esmalte. Ao mesmo tempo existe uma séria dificuldade de controle de temperatura de queima, pois a formação de líquidos acontece num intervalo de temperatura bastante restrito, levando o material a fundir ou não densificar em variações de dezenas de graus Celsius da temperatura ótima de queima. A modificação das matériasprimas pode afetar tanto a fração quanto a temperatura da fase líquida formada durante o aquecimento [7-9].

No Brasil, bone china tem sido produzida em laboratórios de pesquisa pela substituição de Cornish stone por feldspatos [10], mas se respeitando a composição 50:25:25 (ossos bovinos calcinados:fundentes:caulim). Neste trabalho foi avaliada a modificação de composição de porcelanas fosfáticas utilizando-se como fundente feldspatos. A avaliação das características dos produtos e do comportamento durante a queima foi feita para amostras preparadas nas proporções mássicas de 50:25:25, 50:20:30 e 60:20:20 (OBC:feldspato:caulim) e estudadas por ensaios de dilatometria para verificação da modificação das temperaturas de sinterização. As análises químicas das amostras foram realizadas através de análise de fluorescência de raios $\mathrm{X}$ e os resultados comparados com as composições inglesas tradicionais. A evolução do tamanho de poros e da porosidade total das amostras foi medida através da técnica de intrusão de mercúrio para cerâmicas sinterizadas entre 1000 e $1300{ }^{\circ} \mathrm{C}$. A formação e reação entre as fases cristalinas foram acompanhadas por difração de raios X.

\section{MATERIAIS E MÉTODOS}

Ossos bovinos foram lavados em autoclave para a eliminação do sangue e da maior parte da gordura associada, como descrito em trabalho anterior [11]. O osso bruto então foi seco em estufa a $100{ }^{\circ} \mathrm{C}$ e submetido à calcinação a $700{ }^{\circ} \mathrm{C}$ por $1 \mathrm{~h}$ em forno tipo mufla com introdução de ar comprimido. As condições de lavagem na autoclave e as temperaturas de calcinação foram estabelecidas em trabalhos prévios [10, 11]. Uma vez calcinados, os ossos foram moídos em almofariz de ágata e em seguida em moinho de bolas com jarro e elementos de porcelana por $24 \mathrm{~h}$, utilizando água destilada como fluído de moagem. Em seguida o material foi filtrado e lavado abundantemente com água destilada. $\mathrm{O}$ material obtido foi misturado ao feldspato e ao caulim nas proporções 50:25:25, 60:20:20 e 50:20:30 (OBC:feldspato:caulim) e introduzido novamente em moinho de bolas por $24 \mathrm{~h}$ para moagem dos não plásticos e homogeneização da mistura. Cada mistura foi seca em estufa a aproximadamente $100{ }^{\circ} \mathrm{C}$, e depois desaglomerada em almofariz. O pó resultante foi prensado a seco em prensa uniaxial Carver 3912, com dois tipos de matrizes: três amostras de cada composição com matriz de diâmetro de $4 \mathrm{~cm}$, sendo que cada uma com aproximadamente 5 g e dez amostras feitas com matriz de diâmetro de 1,5 $\mathrm{cm}$ com aproximadamente $1 \mathrm{~g}$ cada amostra. Todas as amostras foram prensadas a $98 \mathrm{MPa}$. As amostras menores foram utilizadas para as análises de intrusão de mercúrio.
Os corpos de prova foram então queimadas em forno tipo mufla com uma velocidade de aquecimento de $2{ }^{\circ} \mathrm{C} / \mathrm{min}$, sem patamar de temperatura, até a temperatura desejada, e depois resfriadas naturalmente. Amostras foram queimadas nas temperaturas de 1000 a $1300{ }^{\circ} \mathrm{C}$, com intervalos de 50 ${ }^{\circ} \mathrm{C}$, para cada composição.

A composição química foi determinada pela técnica de fluorescência de raios X. As amostras foram submetidas à análise química em equipamento PANalytical Axios Pro e a quantificação foi realizada através de padrões de materiais fosfáticos e argilosos.

O acompanhamento das transformações das fases cristalinas foi feito por difração de raios $\mathrm{X}$ em um equipamento Philips X'Pert MPD com radiação $\mathrm{CuK}_{\alpha}$, na rotina $\theta / 2 \theta$ de 2 a $90^{\circ}$, com passo $0,02^{\circ}$ e tempo de permanência $1 \mathrm{~s}$.

Na preparação das amostras para microscopia eletrônica de varredura utilizou-se as pastilhas prensadas com diâmetro de $4 \mathrm{~cm}$. Estas foram embutidas em baquelite de forma a analisar a região transversal da amostra após fratura e polimento. As amostras foram lixadas em água e polidas com pasta de diamante em álcool etílico variando as granulometrias de 6,3 e $1 \mu \mathrm{m}$. A amostra foi recoberta com ouro e analisada em microscópio eletrônico de varredura FEI Quanta 600F. A análise de dilatometria foi feita com dilatômetro digital BP Engenharia RB115. As amostras foram conformadas por prensagem em molde retangular utilizando $98 \mathrm{MPa}$ e depois cortadas para um dimensão final de $5 \times 5 \times 50 \mathrm{~mm}^{3}$. A taxa de aquecimento foi $5{ }^{\circ} \mathrm{C} / \mathrm{min}$ e a atmosfera ar sintético.

\section{RESULTADOS E DISCUSSÃO}

As composições químicas obtidas por fluorescência de raios $X$ das formulações 50:25:25, 60:20:20 e 50:20:30 (OBC:feldspato:caulim) e a composição química de uma massa de bone china comercial Coalport [7] são apresentadas na Tabela I.

Como a massa comercial é composta de caulim, OBC e Cornish stone, a quantidade de óxidos alcalinos fundentes é pequena com relaçãoàs composições estudadas neste trabalho. O feldspato é muito mais rico em óxidos de metais alcalinos que o Cornish stone, e por isto, o aumento significativo dos óxidos fundentes. A alteração da composição química é clara e pode afetar de maneira definitiva a formação e a decomposição das fases, suas temperaturas de reação e a própria sinterização. $\mathrm{O}$ diagrama de fases do sistema $\mathrm{CaO}$ $\mathrm{P}_{2} \mathrm{O}_{5}-\mathrm{SiO}_{2}$, mostrando a comparação das composições químicas deste trabalho com aquela comercial, é apresentado na Fig. 1. A passagem da formulação 50:20:30 para 50:25:25 e depois 60:20:20 se afasta do $\mathrm{SiO}_{2}$ caminhando em direção do composto tri-cálcio fosfato, mas se mantendo na região de formação de dois líquidos. É de se esperar, então, que nesta condição, e a depender da quantidade total de alcalinos e da razão com a quantidade de sílica, o sistema apresente temperatura diferente na formação dos líquidos e também composição química própria de cada formulação. A 
Tabela I - Comparação da composição química de diferentes formulações de bone china. [Table I - Chemical composition of different bone china formulations.]

\begin{tabular}{cccccccccccccc}
\hline & $\mathrm{SiO}_{2}$ & $\mathrm{Al}_{2} \mathrm{O}_{3}$ & $\mathrm{CaO}$ & $\mathrm{P}_{2} \mathrm{O}_{5}$ & $\mathrm{Na}_{2} \mathrm{O}$ & $\mathrm{MgO}$ & $\mathrm{K}_{2} \mathrm{O}$ & fundentes & $\mathrm{CaO} / \mathrm{P}_{2} \mathrm{O}_{5}$ & $\mathrm{CaO} / \mathrm{SiO}_{2}$ & $\mathrm{CaO} / \mathrm{Al}_{2} \mathrm{O}_{3}$ & $\mathrm{SiO}_{2} / \mathrm{fundentes}$ & $\mathrm{K}_{2} \mathrm{O} / \mathrm{NaO}$ \\
\hline $50: 25: 25$ & 29.69 & 14.61 & 28.36 & 22.20 & 1.17 & 0.70 & 3.26 & 5.14 & 1.28 & 0.96 & 1.94 & 5.78 & 2.79 \\
$60: 20: 20$ & 23.60 & 11.65 & 33.79 & 26.44 & 1.15 & 0.79 & 2.58 & 4.53 & 1.28 & 1.43 & 2.90 & 5.21 & 2.24 \\
$50: 20: 30$ & 30.49 & 13.48 & 28.21 & 22.06 & 1.28 & 0.70 & 3.78 & 5.76 & 1.28 & 0.93 & 2.09 & 5.29 & 2.96 \\
Coalport [7] & 42.88 & 15.06 & 23.16 & 16.30 & & & & 2.60 & 1.42 & 0.54 & 1.54 & 16.49 & \\
\hline
\end{tabular}

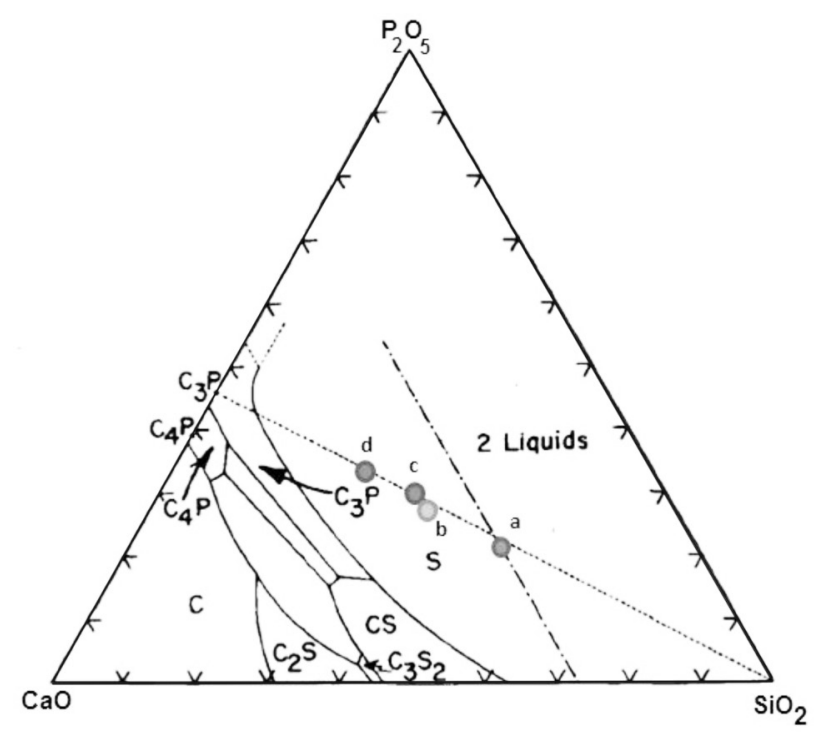

Figura 1: Diagrama de equilíbrio de fases do sistema CaO- $\mathrm{P}_{2} \mathrm{O}_{5}$ $\mathrm{SiO}_{2}$. (a) Bone China Coalport; (b) 50:20:30, (c) 50:25:25 e (d) 60:20:20.

[Figure 1: High-temperature phase equilibrium of the system $\mathrm{CaO}$ $\mathrm{P}_{2} \mathrm{O}_{5}-\mathrm{SiO}_{2}$ (a) Bone China Coalport; (b) 50:20:30, (c) 50:25:25e (d) 60:20:20.1

composição 50:20:30 é a que apresenta a maior quantidade absoluta de fundentes, contudo a razão da quantidade de $\mathrm{SiO}_{2}$ com respeito à quantidade de fundentes é maior para a composição 60:20:20. A formação do líquido é fundamental, pois está diretamente relacionada à temperatura de queima da porcelana.

Os dados apresentados na Fig. 2, que mostra a retração linear em função da temperatura de queima para as amostras de bone china, reforçam os resultados da análise da composição química discutido anteriormente.

A composição 60:20:20 sinteriza na menor temperatura, possivelmente porque contem a menor relação $\mathrm{SiO}_{2} /$ fundentes (Tabela I) o que reduziria a viscosidade do líquido formado. Para todas as amostras foram verificadas retrações importantes em temperaturas próximas a 500 e $900{ }^{\circ} \mathrm{C}$ que não podem ser vistas nas amostras calcinadas a 1000 ${ }^{\circ} \mathrm{C}$. As transformações estão relacionadas à desidratação e decomposição do caulim [1]. Uma característica muito importante da sinterização de porcelanas é a evolução do tamanho e volume dos poros durante a queima. Isto, pois a esmaltação das porcelanas é feita em um corpo poroso que é geralmente pré-queimado a temperaturas em torno

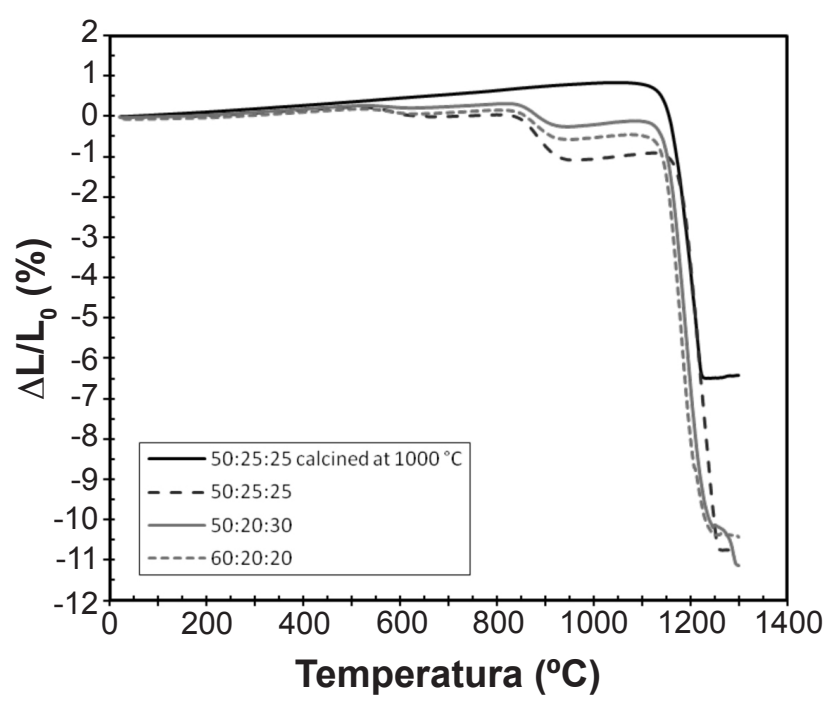

Figura 2: Análise dilatométrica comparativa de diferentes formulações de bone china em função da temperatura de sinterização com taxa de aquecimento de $5^{\circ} \mathrm{C} / \mathrm{min}$.

[Figure 2: Dilatometric analysis of different compositions of bone china and sintering with a heating rate of $5^{\circ} \mathrm{C} / \mathrm{min}$.]

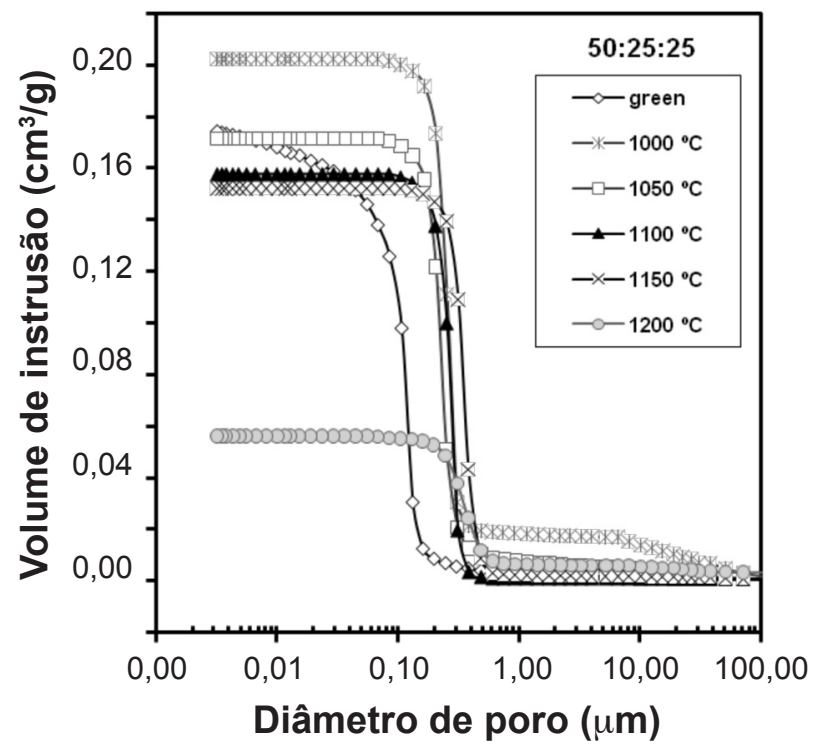

Figura 3: Análise de intrusão de mercúrio das amostras de porcelana de ossos bovinos calcinados nas composições 50:25:25 não sinterizada e sinterizadas a $1000,1050,1100,1150$ e $1200^{\circ} \mathrm{C}$ com taxa de aquecimento de $2{ }^{\circ} \mathrm{C} / \mathrm{min}$.

[Figure 3: Pore size distribution of bone china sintered at 1000, 1050, 1100, 1150 e $1200{ }^{\circ} \mathrm{C}$ with a heating rate of $2{ }^{\circ} \mathrm{C} / \mathrm{min}$ obtained by $\mathrm{Hg}$ intrusion.] 


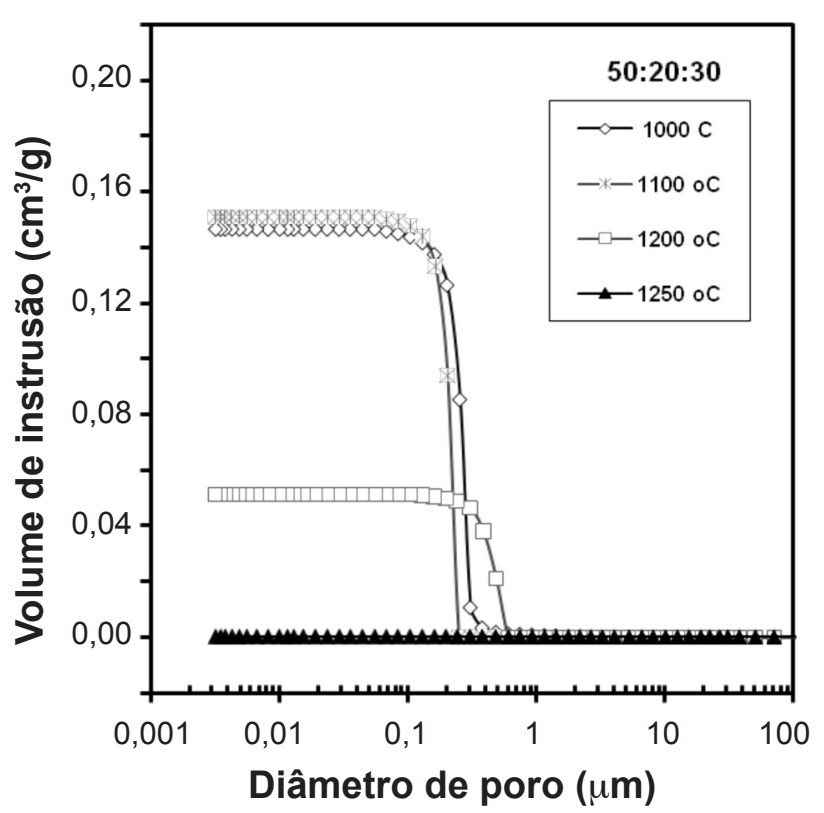

Figura 4: Análise de intrusão de mercúrio das amostras de porcelana de ossos bovinos calcinados nas composições 50:20:30 e sinterizados até $1000,1100,1200$ e $1250{ }^{\circ} \mathrm{C}$ com taxa de aquecimento de $2{ }^{\circ} \mathrm{C} / \mathrm{min}$.

[Figure 4: Pore size distribution of bone china with composition 50:20:30 sintered at 1000, 1100, 1200 e $1250{ }^{\circ} \mathrm{C}$ with a heating rate of $2{ }^{\circ} \mathrm{C} / \mathrm{min}$ obtained by $\mathrm{Hg}$ intrusion.]

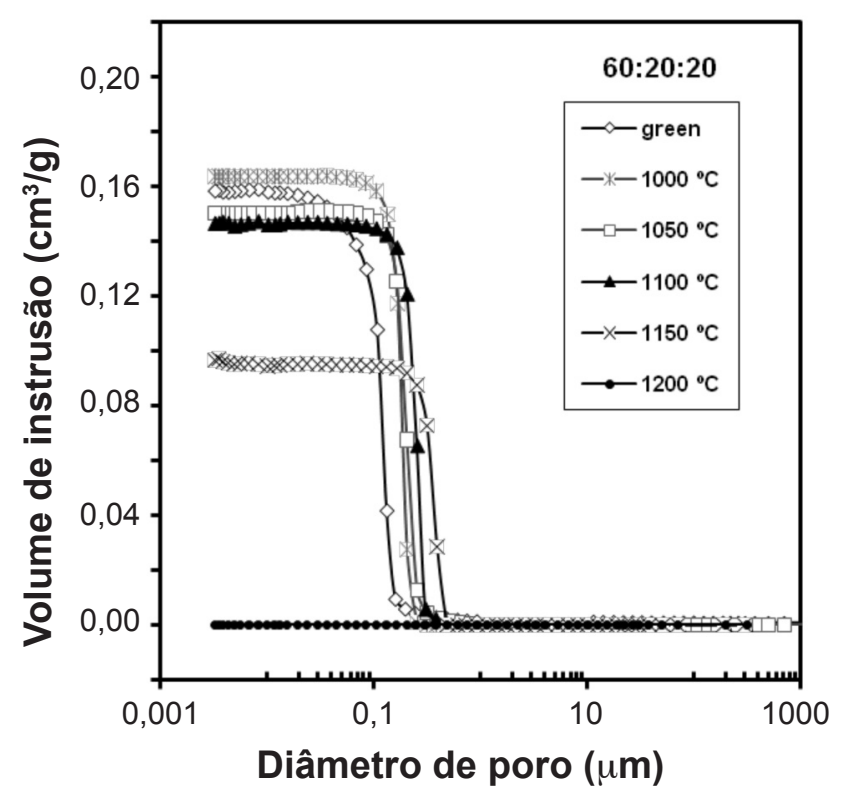

Figura 5: Análise de intrusão de mercúrio das amostras de porcelana de ossos bovinos calcinados nas composições 60:20:20 e sinterizados até $1000,1050,1100,1150$ e $1200{ }^{\circ} \mathrm{C}$ com taxa de aquecimento de $2{ }^{\circ} \mathrm{C} / \mathrm{min}$.

[Figure 4: Pore size distribution of bone china of composition 60:20:20 sintered at 1000, 1050, 1100, 1150 e $1200{ }^{\circ} \mathrm{C}$ with a heat rate of $2{ }^{\circ} \mathrm{C} / \mathrm{min}$ obtained by $\mathrm{Hg}$ intrusion.]

de $1000{ }^{\circ} \mathrm{C}$, onde a maioria dos voláteis é eliminada e as reações de decomposição do caulim terminaram. Além disto, mostram a evolução da microestrutura e a variação do volume de poros abertos, ou seja, da densidade aparente do corpo cerâmico. A medida da distribuição de tamanho e volume total de poros obtidos por porosimetria ao mercúrio das amostras 50:25:25, 50:20:30 e 60:20:20 são mostrados respectivamente nas Figs. 3, 4 e 5.

A Fig. 3 mostra que as amostras apresentam uma forte variação, tanto do tamanho médio como do volume de poros total de antes da queima para após a queima a $1000{ }^{\circ} \mathrm{C}$. A queima a $1000^{\circ} \mathrm{C}$ altera o volume livre, muito possivelmente

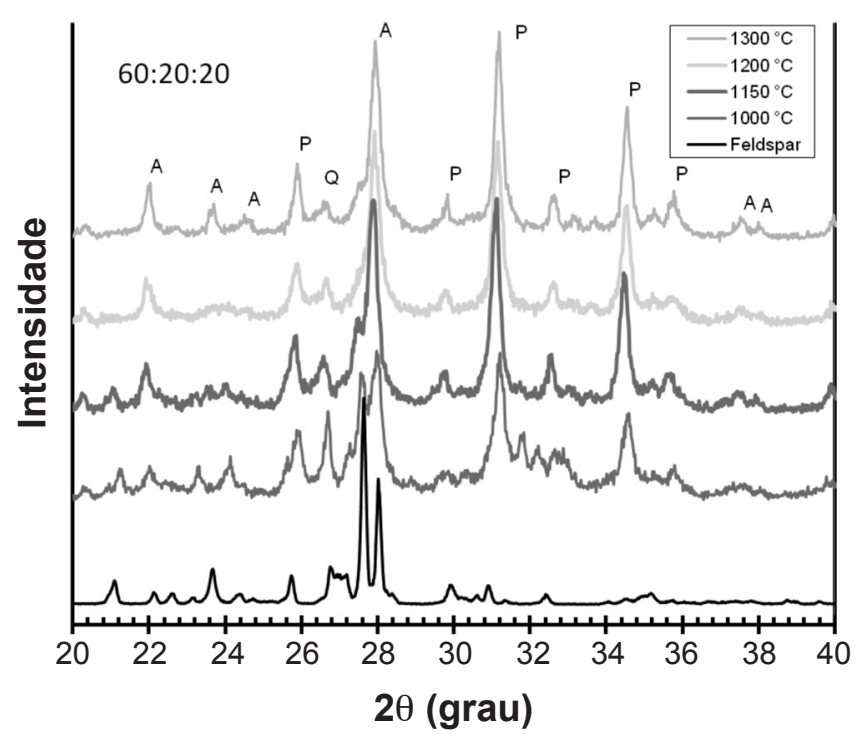

Figura 6: Difratogramas de raios $\mathrm{X}$ de porcelanas de ossos bovinos na proporção 60:20:20 e sinterizadas a 1000, 1150, 1200 e $1300^{\circ} \mathrm{C}$ $(\mathrm{Q}=$ quartzo, $\mathrm{A}=$ Anortita e $\mathrm{P}=$ fosfato de cálcio). $\mathrm{O}$ difratograma do feldspato é colocado como referência.

[Figure 6: X-ray diffraction patterns of bone china samples 60:20:20 sintered at 1000, 1150,1200 and $1300{ }^{\circ} \mathrm{C}(Q=$ quartz, $A$ $=$ Anortite and $P=$ tri-calcium phosphate).]

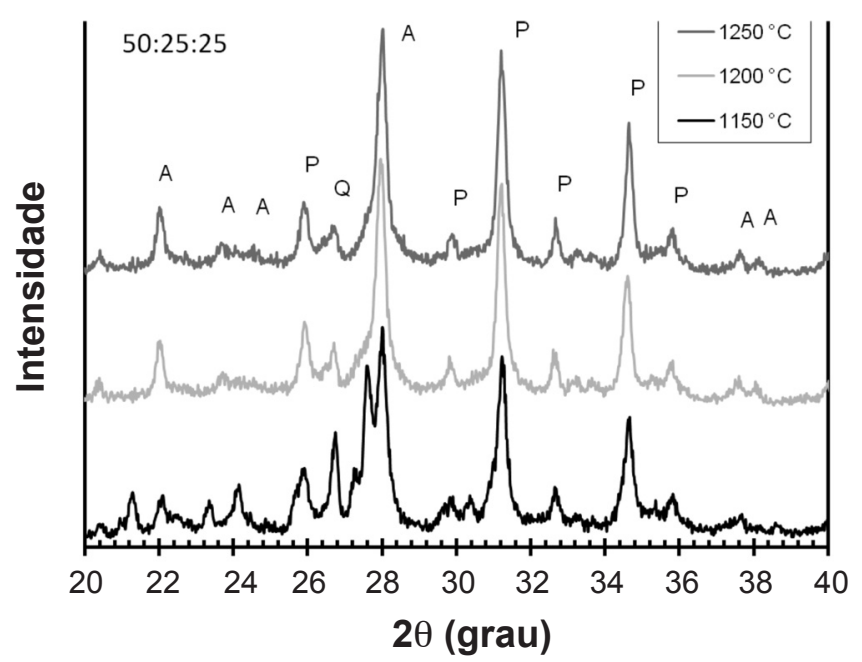

Figura 7: Difratogramas de raios $\mathrm{X}$ de porcelanas de ossos bovinos na proporção 50:25:25 e sinterizadas a 1150,1200 e $1250^{\circ} \mathrm{C}(\mathrm{Q}=$ quartzo, $\mathrm{A}=$ Anortita e $\mathrm{P}=$ tri-fosfato de cálcio).

[Figure 7: X-ray diffraction patterns of bone china samples 50:25:25 sintered at 1150,1200 and $1250{ }^{\circ} \mathrm{C}(Q=$ quartz, $A=$ Anortite and $P=$ tri-calcium phosphate).] 

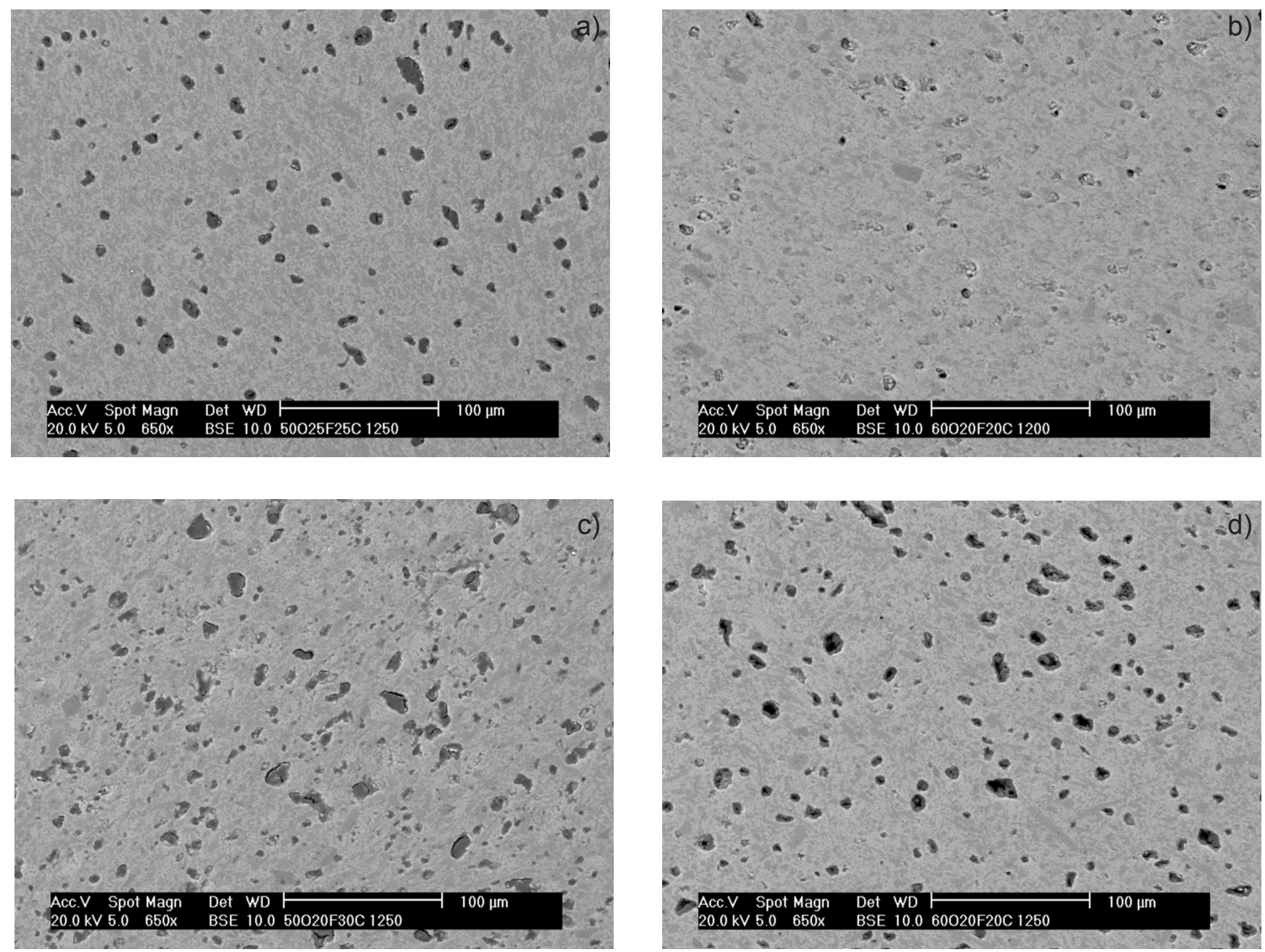

Figura 8: Micrografias obtidas por microscopia eletrônica de varredura de amostras de porcelana contendo diferentes proporções de OBC, caulim e feldspato, sinterizadas em várias temperaturas. (A) 50:35:25 sinterizada a $1250{ }^{\circ} \mathrm{C}$. (B) $60: 20: 20$ sinterizada a $1200{ }^{\circ} \mathrm{C}$, (C) 50:20:30 sinterizada a $1250{ }^{\circ} \mathrm{C}$ e (D) $60: 20: 20$ sinterizada a $1250{ }^{\circ} \mathrm{C}$.

[Figure 8: SEM micrographs of porcelain samples containing different amounts of bone ash, kaolin and feldspar. (A) 50:35:25 sintered at $1250{ }^{\circ} \mathrm{C}$. (B) 60:20:20 sintered at $1200{ }^{\circ} \mathrm{C}, 50: 20: 30$ sintered at $1250{ }^{\circ} \mathrm{C}$ and $60: 20: 20$ sintered at $\left.1250{ }^{\circ} \mathrm{C}.\right]$

devido à decomposição da matéria-prima e eliminação dos voláteis. Assim, a esmaltação feita antes ou depois da préqueima tem uma relação direta com a viscosidade do esmalte e da distribuição granulométrica do mesmo. O crescimento do tamanho dos poros ocorre com o aumento da temperatura de queima, sendo que a maior variação ocorre entre a amostra crua e a sinterização a $1000{ }^{\circ} \mathrm{C}$. A partir de $1000{ }^{\circ} \mathrm{C}$ ocorre a densificação das amostras pela eliminação do volume total de poros, sendo que a maior variação é encontrada entre 1150 e $1200{ }^{\circ} \mathrm{C}$, o que está coerente com os dados de dilatometria apresentados na Fig. 2. A formação da fase vítrea ocorre neste intervalo e em grande quantidade, o que acarreta forte sinterização via fase líquida. Comportamentos semelhantes são observados para o estudo da sinterização das amostras 50:20:30 e 60:20:20, ou seja aumento do volume e do tamanho médio de poros da amostra crua para a sinterização de $1000^{\circ} \mathrm{C}$ (Figs. 4 e 5). Contudo, como pode ser visto na Fig. 5, a amostra 60:20:20 sinterizada a $1200{ }^{\circ} \mathrm{C}$ foi completamente densificada. Este comportamento está de acordo com a curva de retração linear com a temperatura da Fig. 2 e com os dados de composição química apresentados na Tabela I. Assim, a amostra 60:20:20 que tem a menor razão $\mathrm{SiO}_{2}$ /fundentes deve formar vidros a mais baixa temperatura e também de menor viscosidade, o que faz com que densifique a temperaturas menores e mais rapidamente.

A análise de difração de raios $X$ das amostras 60:20:20 e 50:25:25, respectivamente Figs. 6 e 7, mostram que após a queima as fases formadas são típicas da bone china, ou seja, anortita e tri-cálcio fosfato [12, 13]. A decomposição do feldspato, que no sistema age como fundente, ocorre entre 1150 e $1200{ }^{\circ} \mathrm{C}$ e igualmente para as duas amostras. Isto reforça a tese de que a composição química do vidro formado deve ser mais significativa para a sinterização que a temperatura de formação do vidro em si.

O reflexo da boa sinterização para a microestrutura na amostra com composição 60:20:20 queimadas a $1200{ }^{\circ} \mathrm{C}$ é visto nas micrografias da Fig. 8 .

A comparação com as outras amostras, inclusive em 
temperaturas superiores, revela que a composição 60:20:20 sinterizada na temperatura de $1200^{\circ} \mathrm{C}$ leva a formação de uma microestrutura homogênea com baixa porosidade. A amostra 60:20:20 sinterizada a $1250{ }^{\circ} \mathrm{C}$ apresenta porosidade aberta superior àquela da amostra sinterizada a $1200{ }^{\circ} \mathrm{C}$. O surgimento de uma porosidade com o aumento da temperatura de queima de materiais contendo OBC já foi observada em trabalho anterior e supõe-se que a formação da porosidade posterior à densificação completa possa estar relacionada à liberação de voláteis, como por exemplo, a água advinda da decomposição da hidroxiapatita, principal fase do OBC.

\section{CONCLUSÕES}

A modificação das proporções e tipos das matériasprimas originais, ou seja, a substituição de Cornish stone por feldspato para a fabricação de bone china acarreta numa alteração das proporções óxidos fundentes $/ \mathrm{SiO}_{2}$. Quando fabricada com Cornish stone, a composição é de 50:25:25 (OBC:caulim: Cornish stone). A fabricação de bone china nesta proporção com OBC:caulim:feldspato já apresenta uma maior fundência e uma temperatura de sinterização inferior, mas muito próxima, da composição original inglesa. A modificação para a composição 60:20:20 faz com que ocorra um aumento da relação fundentes $/ \mathrm{SiO}_{2}$ que leva a uma facilitação da sinterização devido à redução da viscosidade do vidro formado durante o processo. Nesta composição, o material sinteriza a $1200{ }^{\circ} \mathrm{C}$, que é cerca de $80{ }^{\circ} \mathrm{C}$ abaixo da temperatura de queima da composição inglesa original e apresenta uma microestrutura final muito homogênea e de baixa porosidade. Estudos de resistência mecânica à fratura e ao impacto, translucidez e alvura, e também de esmaltação são necessários para verificar o potencial industrial desta nova formulação.

\section{AGRADECIMENTOS}

À FAPESP (Proc. 03/12721-2).

\section{REFERÊNCIAS}

[1] W. M. Carty, U. Senapati, J. Am. Ceram. Soc. 81, 1 (1998) 3.

[2] P. Rado, An Introduction to the Technology of Pottery, $2^{\text {nd }}$ Ed., Pergamon Press, Oxford, Inglaterra (1988) p. 266.

[3] C. E. L. Franklin, A. J. Forrester, Trans. Brit. Ceram. Soc. 74, 4 (1975) 141.

[4] A. Kara, R. Stevens, J. Eur. Ceram. Soc. 22, 7 (2002) 1095 .

[5] A. Kara, R. Stevens, J. Eur. Ceram. Soc. 22, 7 (2002) 1103 .

[6] T. Ichiko, J. Ceram. Soc. Jap. 102, 5 (1994) 471.

[7] P. D. S. S. Pierre, J. Am. Ceram. Soc. 37, 6 (1954) 243.

[8] P. D. S. S. Pierre, J. Am. Ceram. Soc. 38, 6 (1955) 217.

[9] P. D. S. S. Pierre, J. Am. Ceram. Soc. 39, 4 (1956) 147.

[10] R. Y. Miyahara, D. Gouvêa, S. M. Toffoli, Cerâmica 53, 327 (2007) 234.

[11] D. Gouvêa, S. Bernard, G. A. V. Alatrista, S. M. Tofolli, Cerâmica 53 (2007) 423.

[12] A. Kara, R. Stevens, J. Eur. Ceram. Soc. 22, 5 (2002) 737.

[13] A. Kara, R. Stevens, J. Eur. Ceram. Soc. 22, 5 (2002) 731.

(Rec. 18/09/2009, Ac. 27/03/2010) 